\title{
Detecção de corrosão em concreto armado com termografia infravermelha e ultrassom
}

\author{
Detection of corrosion in reinforced concrete with \\ infrared thermography and ultrasound
}

\begin{abstract}
J oaquin Humberto Aquino Rocha
Yêda Vieira Póvoas

\section{Resumo}

A

corrosão do aço é uma das principais manifestações patológicas em concreto armado. Sua detecção precoce pode evitar tanto custosos reparos quanto danos aos usuários. Este artigo propõe o uso da termografia infravermelha e do ultrassom para a detecção de corrosão em concreto armado. A metodologia consistiu na elaboração de 6 corpos de prova de (30x20x10) cm com a inserção de três barras de aço de 12,5 mm com cobrimentos iguais a $2,5 \mathrm{~cm}, 5,0 \mathrm{~cm}$ e $7,5 \mathrm{~cm}$, os mais utilizados e recomendados nas estruturas de concreto armado. Os corpos de prova foram submetidos a um processo de corrosão acelerada de forma diferenciada com o objetivo de analisar três diferentes graus de corrosão. Posteriormente foi realizado o ensaio de termografia infravermelha e, finalmente, de ultrassom. Os resultados mostraram que a termografia infravermelha tem muitas limitações na detecção da corrosão, mas essas limitações são reduzidas no período da manhã, em estados muito avançados de deterioração e em aços com pequenos cobrimentos. Por outro lado, o ultrassom apresentou clara distinção nos resultados entre os corpos de prova, uma vez que a velocidade de propagação de onda varia de acordo com o grau de corrosão e a qualidade do concreto. Embora ambos os ensaios apresentem algumas limitações, a combinação deles permite melhor detecção do problema, uma vez que a termografia pode localizar as áreas afetadas e o ultrassom pode caracterizar melhor a situação ao comparar essas áreas com outras intactas do mesmo concreto.

Palavras-chave: Corrosão. Termografia infravermelha. Ultrassom. Concreto armado.

${ }^{1} \mathrm{~J}$ oaquin Humberto Aquino

Rocha

${ }^{1}$ Universidade de Pernambuco Recife - PE - Brasil

${ }^{2}$ Yêda Vieira Póvoas ${ }^{2}$ Universidade de Pernambuco Recife - PE - Brasil

Recebido em 05/04/18

Aceito em 13/10/18

\section{Abstract}

Steel corrosion is one of the main pathological manifestations found in reinforced concrete. Its early detection can avoid costly repairs and damage to users. This paper proposes using infrared thermography and ultrasound to detect corrosion in reinforced concrete. The methodology consisted of preparing six specimens of $30 \times 20 \times 10 \mathrm{~cm}$ each including three 12.5- $\mathrm{mm}$ steel bars inserted and 2.5, 5.0 and $7.5-\mathrm{cm}$ coatings. Those are the most commonly used and and recommended types of coating for reinforced concrete structures. The test specimens were subjected to an accelerated corrosion process, in a differentiated manner, in order to analyze three different degrees of corrosion. Subsequently, the specimens were submitted to infrared thermography tests and finally, ultrasound tests. The results showed that infrared thermography has many limitations regarding corrosion detection, but those limitations are reduced during the morning period; in very advanced conditions of deterioration, and on steel covered with only limited coating. On the other hand, the ultrasound showed a clear distinction in the results for the specimens, since wave propagation speed varies according to the corrosion degree and the quality of the concrete. Even though both tests present some limitations, using them in combination is a more effective way to detect the problem, since thermography can locate affected areas and ultrasound can better characterize any problems by comparing these areas against other intact concrete areas.

Keywords: Corrosion. Infrared thermography. Ultrasound. Reinforced concrete.
\end{abstract}




\section{Introdução}

A corrosão do aço é uma das principais causas de deterioração e falha em estruturas de concreto. A corrosão pode ser iniciada por íons cloreto ou através de dióxido de carbono; no primeiro caso, a corrosão provoca a ruptura do filme passivo, pite e fratura do arame; no caso do dióxido de carbono, existe a formação de óxido de ferro e, por sua vez, a expansão das barras de aço, o que gera esforços de tração no concreto (MEIRA, 2017; MEHTA; MONTEIRO, 2013). A condição é progressiva até a fissuração e o desprendimento do concreto, o que compromete a integridade estrutural e a funcionalidade da estrutura (BAEK et al., 2012; OH et al., 2013).

A detecção precoce da corrosão pode reduzir os custos de reparação, bem como evitar grandes consequências, como o colapso das estruturas e danos pessoais. No entanto, a detecção da corrosão é difícil nos estágios iniciais, ainda mais quando feita de forma não destrutiva (HIASA, 2016), pois, normalmente, a inspeção desse problema ocorre quando já existem sinais externos no concreto ou este está muito deteriorado, o que representa um cenário desfavorável e indesejável (AGGELIS et al., 2010).

Alguns dos métodos não destrutivos utilizados para a detecção da corrosão podem ser as medidas do potencial de circuito aberto ou de corrosão, da resistividade elétrica do concreto, da resistência à polarização pela técnica de polarização linear ou espectroscopia de impedância eletroquímica, entre outros. Embora forneçam informações importantes, em alguns casos os resultados podem ser subjetivos e afetados por vários fatores. De acordo com as características da estrutura inspecionada, pode ser necessário o contato direto com o aço, o que implica a ruptura parcial do concreto para sua execução (BAEK et al., 2012; ZOU et al., 2015).

Apesar disso, na atualidade há vários testes não destrutivos com o potencial de detectar diferentes anomalias no concreto, e uma combinação entre eles pode complementar os resultados e ajudar nos trabalhos de diagnóstico (ZOU et al., 2015; ALFREDO-CRUZ et al., 2015; OH et al., 2013; AGGELIS et al., 2010). Nesse sentido, a termografia infravermelha junto com o ultrassom são ferramentas alternativas para a inspeção de estruturas de concreto armado porque não precisam contato direto com o aço e são mais confiáveis do que apenas a inspeção visual.

A termografia infravermelha é uma técnica não destrutiva capaz de detectar defeitos internos no concreto através da análise da temperatura da superfície, incluindo produtos de corrosão, bem como destacamentos e vazios (HIASA; BIRGUL; CATBAS, 2017). A técnica não permite o contato direto com a estrutura e é capaz de analisar áreas maiores, o que permite inspeções mais eficazes. Além disso, seu uso inclui diferentes aplicações na engenharia civil, sendo cada vez mais uma ferramenta consolidada na área das inspeções (BARREIRA; ALMEIDA; DELGADO, 2016; WATASE et al., 2015; WASHER, 2012).

O ensaio de ultrassom baseia-se na propagação de ondas ultrassônicas no material inspecionado entre dois transdutores, emissor e receptor, em que a velocidade de propagação fornece informações sobre algumas propriedades do concreto, como módulo de elasticidade e massa específica (CÁNOVAS, 1998). Não obstante, como as ondas ultrassônicas também são influenciadas pela existência de danos no material, o ensaio é usado para detectar anomalias no concreto e para caracterizá-las (AGGELIS et al., 2010; HERNANDEZ-VALLE; CLOUGH; EDWARDS, 2014).

Apesar das vantagens e capacidades da termografia e do ultrassom para a inspeção, ainda existem incertezas quanto a sua aplicação específica na detecção de alguns problemas do concreto armado, entre eles a corrosão (GEHLOT et al., 2016; WASHER; FENWICH; BOLLENI, 2009; WASHER, 2012; KEE et al., 2012; GUCUNSKI et al., 2013; WATASE et al., 2015; VAGHEFI et al., 2015), uma vez que há poucos trabalhos que tratam dessa temática.

Na atualidade existem poucas normas que regem a execução desses ensaios com relação à corrosão. Por esse motivo, é importante a realização de pesquisas para determinar a capacidade e a confiabilidade dessas técnicas analíticas, além de procurar combinações com outros ensaios não destrutivos para facilitar a inspeção da corrosão e de outras manifestações patológicas.

Nesse sentido, o presente artigo propõe o uso da termografia infravermelha e do ensaio de ultrassom para a detecção de corrosão em concreto armado, considerando que suas características e princípios de análise podem ser aplicados a esse tipo de problema (AMERICAN..., 2011). Além disso, podem estabelecer uma combinação e complementação dos resultados obtidos para determinar os melhores horários de inspeção e definir as limitações na detecção de corrosão em diferentes graus e em diferentes qualidades de concreto, com o uso de termografia passiva e, no caso do ensaio de ultrassom, transmissão direta. 


\section{Programa experimental}

Para alcançar os objetivos desta pesquisa foram moldados 6 corpos de prova de concreto armado (CP1, CP2, CP3, CP4, CP5 e CP6) de (20x30x10) cm com a inserção de três barras de aço de diâmetro $12,5 \mathrm{~mm}$ em cada corpo de prova a $2,5 \mathrm{~cm}, 5,0 \mathrm{~cm}$ e 7,5 cm de cobrimento para o estudo da corrosão para diferentes qualidades de concreto, cobrimentos e graus de corrosão. Os cobrimentos foram selecionados considerando os mais utilizados no concreto armado, além das recomendações da NBR 6118 (ABNT, 2014). Incialmente foi realizado um processo de corrosão acelerada nos corpos de prova em três graus diferentes: 2 corpos de prova sem corrosão e 4 com corrosão acelerada, sendo 2 destes durante 28 dias e os outros 2 durante 56 dias. Posteriormente todos os corpos de prova foram avaliados por meio da termografia infravermelha, e finalmente, para melhor caracterização da corrosão, o ultrassom foi utilizado.

\section{Corpos de prova}

Dois tipos de concreto foram fabricados com relação a/c de 0,6 (CP1, CP3 e CP5) e de 0,5 (CP2, CP4 e CP6). A proporção cimento:areia:brita utilizada foi de 1:2,67:2,80. Utilizou-se o anidrido de cloreto de cálcio em pó para melhorar a condutividade elétrica do concreto e induzir a corrosão ( $2 \%$ de íons Cl- em relação à massa de cimento, adicionado ao cimento em pó).

O aglomerante hidráulico utilizado foi o CPII Z-32, correspondente ao Pozzolan-Modified Portland da
ASTM C-595 (AMERICAN..., 2017). Foi determinada a composição granulométrica do agregado graúdo e miúdo conforme a NBR NM 248 (ABNT, 2003). De acordo com os resultados, os agregados estavam no limite da zona utilizável para sua utilização em concreto, conforme a NBR 7211 (ABNT, 2009). O aço utilizado foi o CA-50, segundo características da NBR 7480 (ABNT, 2007a).

As características dos 6 corpos de prova são mostradas na Tabela 1, e o detalhe construtivo é mostrado na Figura 1.

Durante o processo de concretagem foram moldados 4 cilindros para cada relação a/c, com um total de 8 cilindros de $10 \mathrm{~cm}$ de diâmetro por $20 \mathrm{~cm}$ de altura, seguindo o procedimento estabelecido na NBR 5738 (ABNT, 2015), para posterior determinação da resistência à compressão do concreto, como também de sua densidade. As formas foram retiradas aproximadamente 24 h após a concretagem; posteriormente, os corpos de prova tanto prismáticos quanto cilíndricos sofreram o processo de cura em uma solução de hidróxido de cálcio, conforme indica a NBR 5738 (ABNT, 2015). Após o processo de cura, os 8 corpos de prova cilíndricos foram ensaiados para determinar a resistência à compressão, seguindo o procedimento descrito na NBR 5739 (ABNT, 2007b).

A Tabela 2 mostra os resultados da resistência à compressão dos corpos de prova cilíndricos para as duas relações a/c.

Tabela 1 - Características dos corpos de prova com aço

\begin{tabular}{|c|c|c|c|c|}
\hline $\begin{array}{c}\text { Corrosão } \\
(\%)\end{array}$ & $\begin{array}{c}\text { Corpo de } \\
\text { prova }\end{array}$ & Relação a/c & $\begin{array}{c}\text { Cobrimento das } \\
\text { barras }(\mathrm{cm})\end{array}$ & Nome da barra \\
\hline \multirow{6}{*}{0} & \multirow{3}{*}{ CP 1} & \multirow{3}{*}{0,6} & 2,5 & B1 \\
\hline & & & 5,0 & B2 \\
\hline & & & 7,5 & B3 \\
\hline & \multirow{3}{*}{ CP 2} & \multirow{3}{*}{0,5} & 2,5 & B4 \\
\hline & & & 5,0 & B5 \\
\hline & & & 7,5 & B6 \\
\hline \multirow{6}{*}{$\mathrm{X}$} & \multirow{3}{*}{ CP 3} & \multirow{3}{*}{0,6} & 2,5 & B7 \\
\hline & & & 5,0 & B8 \\
\hline & & & 7,5 & B9 \\
\hline & \multirow{3}{*}{ CP 4} & \multirow{3}{*}{0,5} & 2,5 & B10 \\
\hline & & & 5,0 & B11 \\
\hline & & & 7,5 & B12 \\
\hline \multirow{6}{*}{$\mathrm{Y}$} & \multirow{3}{*}{ CP 5} & \multirow{3}{*}{0,6} & 2,5 & B13 \\
\hline & & & 5,0 & B14 \\
\hline & & & 7,5 & B15 \\
\hline & \multirow{3}{*}{ CP6 } & \multirow{3}{*}{0,5} & 2,5 & B16 \\
\hline & & & 5,0 & B17 \\
\hline & & & 7,5 & B18 \\
\hline
\end{tabular}


Figura 1 - Detalhe dos corpos de prova com aço

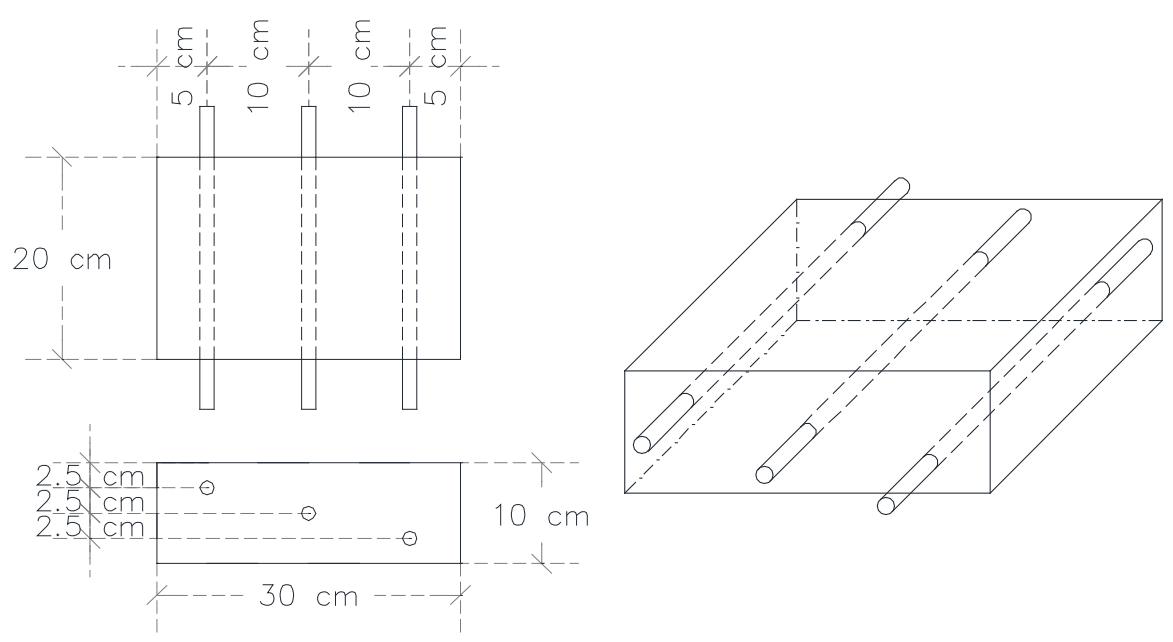

Tabela 2 - Resistência à compressão dos concretos

\begin{tabular}{c|c|c}
\hline \multirow{2}{*}{ Corpos de prova cilíndricos } & \multicolumn{2}{|c}{ Resistência à compressão } \\
\cline { 2 - 3 } & $\mathbf{a} / \mathbf{c}=\mathbf{0 , 6}$ & $\mathbf{a} \mathbf{c}=\mathbf{0 , 5}$ \\
\hline CPC-1 & 24,6 & 30,6 \\
CPC-2 & 23,6 & 33,2 \\
CPC-3 & 27,3 & 31,5 \\
CPC-4 & 25,6 & 33,2 \\
\hline Resistência média à compressão & 25,3 & 32,1 \\
aos 28 dias (MPa) & 1,58 & 1,29 \\
Desvio padrão (MPa) & 6,3 & 4,0 \\
Coeficiente de variação (\%) & 2198 & 2387 \\
Densidade média (kg/m $\left.{ }^{3}\right)$ & \multicolumn{2}{|c}{}
\end{tabular}

\section{Métodos}

\section{Ensaio de corrosão acelerada}

O ensaio de corrosão acelerada consiste na aplicação de corrente contínua usando uma fonte de alimentação digital para a indução da corrosão no aço (MORENO, 2008). Assim, foi utilizada uma fonte de alimentação digital PS-1502DD alternadamente com uma fonte de alimentação Stelltrafo Phyme. Na Tabela 3 são mostradas as características dos equipamentos.

O procedimento adotado foi a aplicação de uma corrente anódica constante entre as barras de aço do corpo de prova e uma placa de alumínio, que corresponde ao inverso de uma proteção catódica com corrente impressa (AHMAD, 2009). Para facilitar a condução e obter distribuição uniforme da corrente, foi colocada uma solução de cloreto de sódio de 3,5\% entre a superfície do corpo de prova e a placa de alumínio, conforme recomendam Baek et al. (2012). Na Figura 2 é mostrado o detalhe do ensaio.

Os corpos de prova foram conectados de dois em dois. As barras de aço foram ligadas a uma intensidade de corrente de $20 \mu \mathrm{A} / \mathrm{cm}^{2}$ nos corpos de prova CP3 e CP4 durante 28 dias; os corpos de prova CP5 e PC6 também recebiam a mesma intensidade de corrente, mas durante 56 dias. Os valores de intensidade de corrente foram medidos de acordo com as recomendações de Moreno (2008) para alcançar um grau teórico de corrosão desejado em um marco de tempo determinado, além de considerar a capacidade da fonte de alimentação. No entanto, na literatura são encontrados diferentes valores de intensidade de corrente (BAEK et al., 2012). Os tempos foram escolhidos a fim de ter dois diferentes graus de corrosão (X\% e Y\%). A Figura 3 mostra a forma de conexão dos corpos de prova. 
Tabela 3 - Características das fontes de alimentação digital

\begin{tabular}{c|c|c}
\hline Modelo & PS-1502DD Yaxun & Stelltrafo Phyme \\
\hline Tensão de saída & DC 0 V a 15 V & $20 \mathrm{~V}$ \\
Ajuste da corrente proteção & $0,6 \mathrm{~A} \mathrm{a} \mathrm{2} \mathrm{A}$ & $12 \mathrm{~A}$ \\
Temperatura de operação & $-5{ }^{\circ} \mathrm{C} \mathrm{a}+40{ }^{\circ} \mathrm{C}$ & - \\
Temperatura de armazenamento & $-10{ }^{\circ} \mathrm{C} \mathrm{a}+40^{\circ} \mathrm{C}$ & - \\
Ondulação e ruído & $\leq 1 \mathrm{mV} \mathrm{RMS}$ & $\leq 1 \mathrm{mV}$ RMS \\
Dimensões & $(17,5 \times 12,5 \times 14,5) \mathrm{cm}$ & $(23 \times 23,6 \times 23,4) \mathrm{cm}$ \\
\hline
\end{tabular}

Fonte: dados fornecidos pelos fabricantes.

\section{Figura 2 - Detalhe do ensaio de corrosão acelerada}

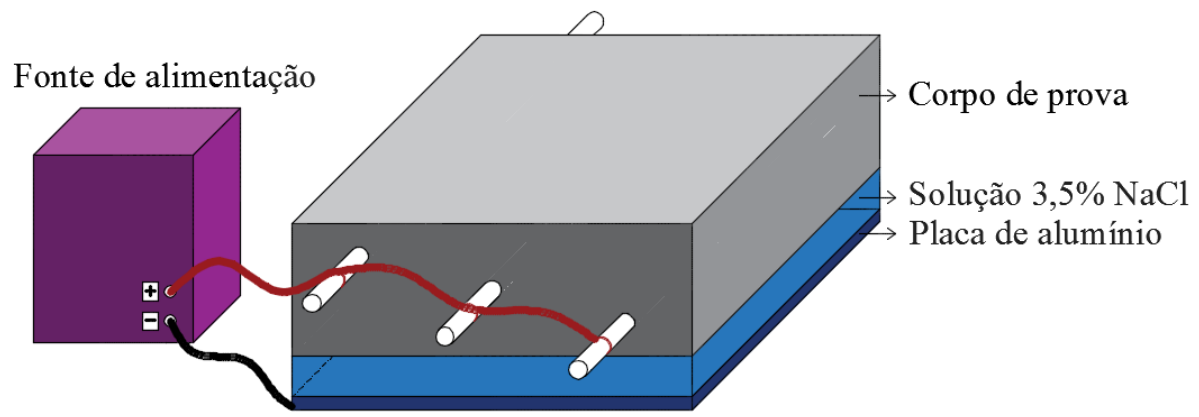

Figura 3 - Conexão dos corpos de prova com a fonte de alimentação

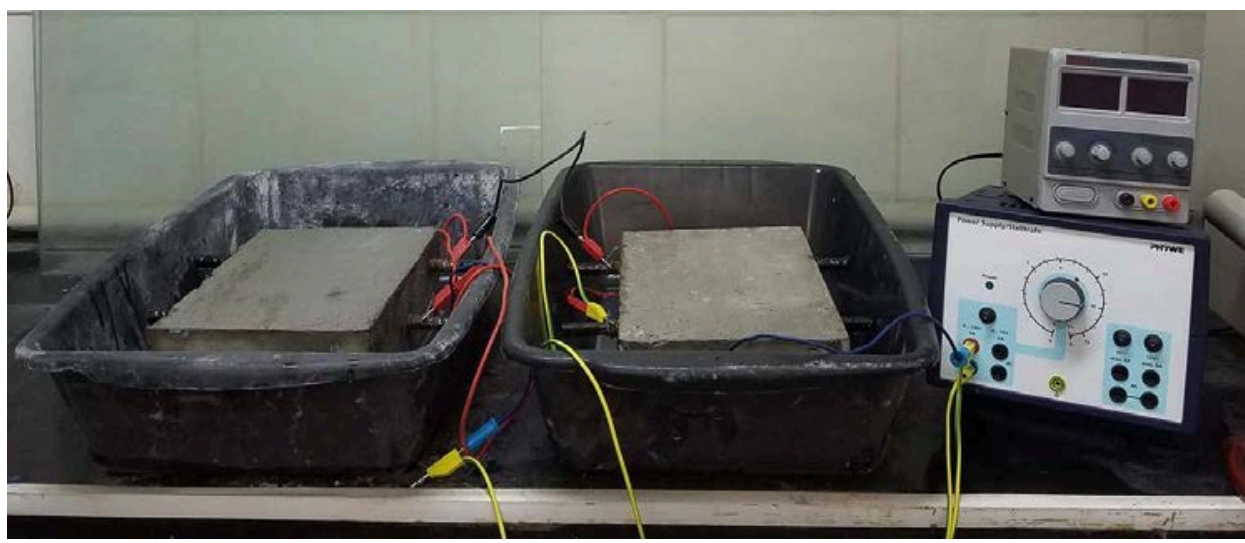

A determinação do grau de corrosão do aço (X\% e Y\%) foi calculada com base em sua perda de massa gravimétrica. Antes do ensaio de corrosão acelerada, a armadura foi limpa e pesada. Terminados os ensaios, o aço foi extraído do concreto e a ferrugem foi removida com uma solução de $\mathrm{HCl}$ a $50 \%$ (volume/volume); depois foi usado um inibidor de corrosão (hexametilenotetramina) em uma concentração de 4 g/l, seguindo o procedimento descrito na norma G199-09 (AMERICAN..., 2014). A decapagem e a pesagem foram feitas até a constância de massa. Durante esse processo foi utilizada uma balança digital com precisão de 0,01 g. Para medir a perda de massa foi aplicada a Equação 1.
$Q_{\text {corr }}=\frac{W_{0}-W_{S}}{W_{0}} \times 100$

Eq. 1

Onde:

Qcorr = quantidade de perda de massa da armadura (\%);

$W_{0}=$ massa da armadura antes do processo de corrosão (g); e

$W_{S}=$ massa da armadura após o processo de corrosão (g).

\section{Ensaio de termografia infravermelha}

O ensaio de termografia infravermelha foi realizado de forma passiva, com o sol como fonte de 
aquecimento, em temperatura ambiente. Foi utilizada uma câmera termográfica FLIR E-60, cujas principais características são apresentadas na Tabela 4.

Após o processo de cura e de corrosão acelerada, os corpos de prova foram levados para um local que permitisse a incidência de radiação solar durante todo o dia, sem ter a interferência de sombras ou outro obstáculo. A Figura 4 mostra a localização e a posição dos corpos de prova.

As medições foram realizadas das $7 \mathrm{~h} 00$ às $21 \mathrm{~h} 00$ para determinar o melhor horário de detecção da corrosão. Os termogramas foram obtidos em intervalos de $60 \mathrm{~min}$, os quais permitiram verificar a evolução da temperatura na superfície dos corpos de prova. Paralelamente foram registradas a temperatura ambiente e a umidade relativa por meio de um termo-higrômetro.

Para a análise dos resultados de contraste térmico foi utilizada a Equação 2.

$\Delta T=T a-T b$

Onde:

$\Delta T=$ diferença de temperatura entre a área afetada por corrosão e a área da superfície do concreto sem problemas $\left({ }^{\circ} \mathrm{C}\right)$;

$\mathrm{Ta}$ = temperatura da área afetada pela corrosão

$\left({ }^{\circ} \mathrm{C}\right)$; e

$\mathrm{Tb}=$ temperatura da superfície do concreto $\left({ }^{\circ} \mathrm{C}\right)$.
Os termogramas foram capturados nos mesmos locais selecionados para a determinação do contraste.

\section{Ensaio de ultrassom}

O ensaio de ultrassom foi realizado depois de finalizado o ensaio de termografia infravermelha. Foi utilizado um equipamento UPV 58-E4800, cujas principais características estão na Tabela 5.

O ensaio foi realizado via transmissão direta, como mostra a Figura 5a, de acordo com o procedimento estabelecido na NBR 8802 (ABNT, 2013). Foi utilizada vaselina como acoplamento dos transdutores ao concreto. Foram feitas três leituras em cada barra de aço e três leituras em locais de concreto intacto, de acordo com a Figura 5b, sendo a média dessas três leituras usada na análise dos resultados.

A velocidade de propagação de onda em cada ponto foi calculada de acordo com a Equação 3, e para a análise foi utilizada a velocidade média dos três pontos de cada barra e do concreto.

$V=d / T$

Onde:

$V$ = velocidade de propagação de onda em cada ponto (m/s);

$d=$ distância entre os transdutores (m); e

$T$ = tempo de propagação de onda fornecido pelo equipamento (s).

Tabela 4 - Características da câmera termográfica FLIR E60

\begin{tabular}{c|c}
\hline Modelo & FLIR E60 \\
\hline Resolução IR & $320 \times 240$ pixels \\
Sensibilidade térmica & $<0,05^{\circ} \mathrm{C}$ \\
Faixa de temperatura & $-20{ }^{\circ} \mathrm{C} \mathrm{e} 650{ }^{\circ} \mathrm{C}$ \\
Precisão & $\pm 2{ }^{\circ} \mathrm{C} \mathrm{ou} \pm 2 \%$ \\
Câmera de vídeo sem iluminação & $3,1 \mathrm{MP}$ \\
Peso & $0,825 \mathrm{~kg}$ \\
\hline
\end{tabular}

Fonte: FLIR (2014).

Figura 4 - (a) Localização, (b) imagem digital e (c) imagem térmica dos corpos de prova

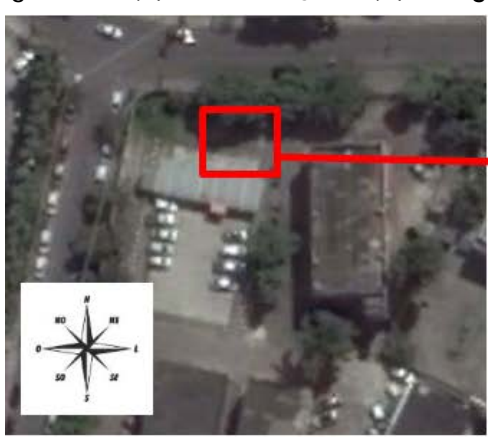

(a)

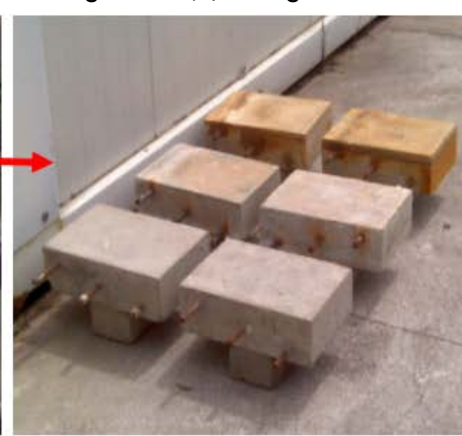

(b)

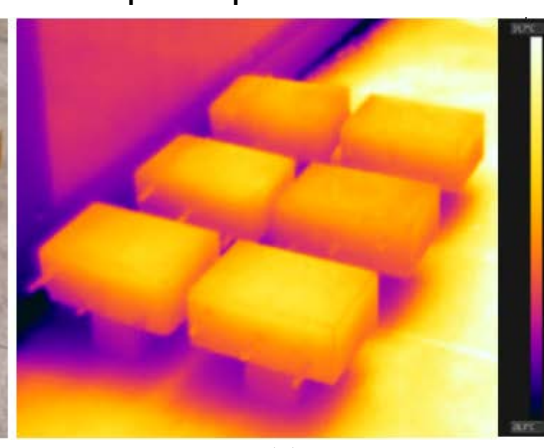

(c) 
Tabela 5 - Características do equipamento UPV 58-E4800

\begin{tabular}{c|c}
\hline Modelo & 58-E4800 \\
\hline Pacote interno de bateria recarregável & $2.400 \mathrm{mAh}$ \\
Medição do tempo de trânsito & $0,1 \mu \mathrm{\mu}$ a $1.999,9 \mu \mathrm{s}$ \\
Taxa de pulso & $1,2,5$ e 10 por segundo \\
Resolução & $0,1 \mu \mathrm{s}$ \\
Faixa de frequência & $24 \mathrm{kHz}$ a $150 \mathrm{kHz}$ \\
Saída do transmissor & $1200 \mathrm{~V}$ \\
Peso & $0,5 \mathrm{~kg}$ \\
\hline
\end{tabular}

Fonte: Controls (2010).

Figura 5 - Posição dos transdutores para a realização do ensaio de ultrassom

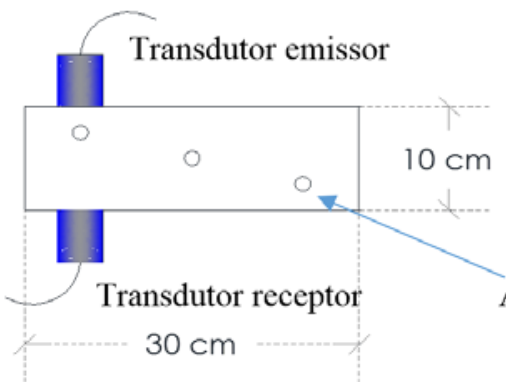

(a)

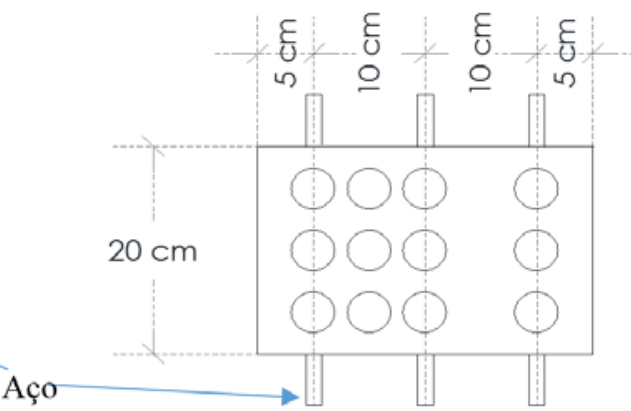

(b)

\section{Discussão dos Resultados}

\section{Determinação do grau de corrosão}

Uma vez realizados os ensaios de termografia infravermelha e ultrassom, as barras foram extraídas do concreto para a determinação da perda de massa. A Tabela 6 mostra os valores de massa iniciais (W0) e finais (WS) e a perda de massa total (Qcorr) de cada barra.

De acordo com a Tabela 6, os corpos de prova CP3 e CP4 apresentaram perda de massa média de $1,79 \%$ e $1,64 \%$ respectivamente. Os corpos de prova CP5 e CP6 tiveram maior porcentagem de perda de massa, 7,4\% e 6,26\% respectivamente, especialmente as barras B13 e B16, que apresentaram maior perda em relação às barras do mesmo corpo de prova, já que ambas estavam a uma distância de 2,5 cm da placa de alumínio durante o ensaio de corrosão acelerada, o que criou maior área de contato e favoreceu o processo de corrosão, havendo um processo de corrosão diferenciado de acordo com o cobrimento das barras, o qual foi mais evidente nos corpos de prova de 56 dias, CP5 e CP6. A Figura 6 mostra algumas barras após o processo de limpeza.

Observa-se que, de acordo com o tamanho das superfícies anódica e catódica das barras e a presença de íons cloreto, gera-se corrosão generalizada e localizada, onde as barras são cobertas com uma camada de óxido castanhoavermelhado, atribuídas aos produtos da corrosão como o óxido de ferro, hematita e magnetita, e hidróxido de ferro, goetita e lepidocrocita, principalmente, os mesmos que originam tensões radiais de tração no concreto, levando a fissuras no concreto.

\section{Ensaio de termografia infravermelha}

As Figuras 7 a 9 mostram os termogramas dos corpos de prova às 7h00, 10h00, 13h00, 16h00, $18 \mathrm{~h} 00$ e 21h00, que permitiram analisar o comportamento geral e evidenciar o ciclo de aquecimento durante as primeiras horas do dia e o ciclo de resfriamento que teve início durante as horas da tarde.

Na Figura 7a pode-se observar o termograma no início do ensaio, 7h00, onde pode ser visto o equilíbrio entre os corpos de prova e o meio ambiente. As Figuras 7b e 8a mostram os termogramas no ciclo de aquecimento do concreto, apresentando temperaturas elevadas. A Figura 8b mostra o termograma no ciclo de resfriamento, em que a temperatura dos corpos de prova diminuiu. As Figuras 9a e 9b mostram o processo de equilíbrio que existe entre os corpos de prova com o meio ambiente, em que são apresentadas menores 
temperaturas do que durante o dia. No entanto, nos termogramas não foi possível observar contrastes térmicos entre as áreas do concreto intacto e as afetadas pela corrosão que permitissem detectar anomalias na superfície do concreto.

Tabela 6 - Perda de peso das barras de aço

\begin{tabular}{|c|c|c|c|c|c|c|c|c|c|}
\hline $\begin{array}{c}\text { Corrosão } \\
(\%)\end{array}$ & $\begin{array}{c}\text { Corpo } \\
\text { de } \\
\text { prova }\end{array}$ & $\begin{array}{c}\text { Relação } \\
\text { a/c }\end{array}$ & $\begin{array}{c}\text { Cobrimento } \\
\text { da barra }\end{array}$ & $W_{0}(g)$ & Ws (g) & $\begin{array}{l}\text { Qcorr } \\
(\%)\end{array}$ & $\begin{array}{c}\text { Média } \\
\text { Qcorr } \\
(\%)\end{array}$ & $\begin{array}{c}\text { Desvio } \\
\text { padrão } \\
(\%)\end{array}$ & $\begin{array}{c}\text { Nome } \\
\text { da } \\
\text { barra }\end{array}$ \\
\hline \multirow{6}{*}{0} & \multirow{3}{*}{$\mathrm{CP} 1$} & \multirow{3}{*}{0,6} & 2,5 & 293,66 & - & - & \multirow{3}{*}{ - } & \multirow{3}{*}{-} & B1 \\
\hline & & & 5,0 & 286,95 & - & - & & & B2 \\
\hline & & & 7,5 & 279,01 & - & - & & & B3 \\
\hline & \multirow{3}{*}{ CP2 } & \multirow{3}{*}{0,5} & 2,5 & 288,51 & - & - & \multirow{3}{*}{-} & \multirow{3}{*}{-} & B4 \\
\hline & & & 5,0 & 285,22 & - & - & & & B5 \\
\hline & & & 7,5 & 278,12 & - & - & & & B6 \\
\hline \multirow{6}{*}{$\begin{array}{l}X(28 \\
\text { dias })\end{array}$} & \multirow{3}{*}{ CP3 } & \multirow{3}{*}{0,6} & 2,5 & 290,45 & 284,41 & 2,08 & \multirow{3}{*}{1,79} & \multirow{3}{*}{0,22} & B7 \\
\hline & & & 5,0 & 278,01 & 273,12 & 1,76 & & & B8 \\
\hline & & & 7,5 & 278,94 & 274,68 & 1,53 & & & B9 \\
\hline & \multirow{3}{*}{ СР 4} & \multirow{3}{*}{0,5} & 2,5 & 281,36 & 275,78 & 1,98 & \multirow{3}{*}{1,64} & \multirow{3}{*}{0,24} & B10 \\
\hline & & & 5,0 & 279,40 & 275,14 & 1,52 & & & B11 \\
\hline & & & 7,5 & 282,56 & 278,56 & 1,42 & & & B12 \\
\hline \multirow{6}{*}{$\begin{array}{l}\text { Y (56 } \\
\text { dias) }\end{array}$} & \multirow{3}{*}{ CP5 } & \multirow{3}{*}{0,6} & 2,5 & 274,57 & 240,65 & 12,35 & \multirow{3}{*}{7,40} & \multirow{3}{*}{3,52} & B13 \\
\hline & & & 5,0 & 277,01 & 262,21 & 5,34 & & & B14 \\
\hline & & & 7,5 & 277,96 & 265,45 & 4,50 & & & B15 \\
\hline & \multirow{3}{*}{ CP6 } & \multirow{3}{*}{0,5} & 2,5 & 276,23 & 248,35 & 10,09 & \multirow{3}{*}{6,26} & \multirow{3}{*}{2,71} & B16 \\
\hline & & & 5,0 & 295,77 & 282,14 & 4,61 & & & B17 \\
\hline & & & 7,5 & 282,03 & 270,51 & 4,08 & & & B18 \\
\hline
\end{tabular}

Figura 6 - Barras depois do processo de corrosão: (a) B1, (b) B7, (c) B15, (d) B13 e (e) B16

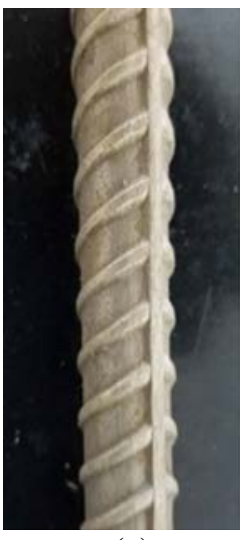

(a)

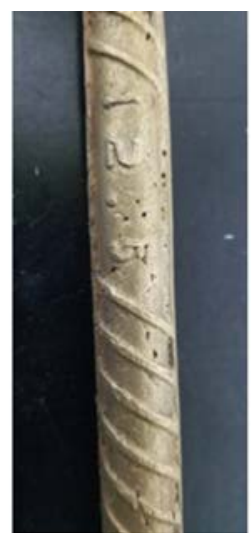

(b)

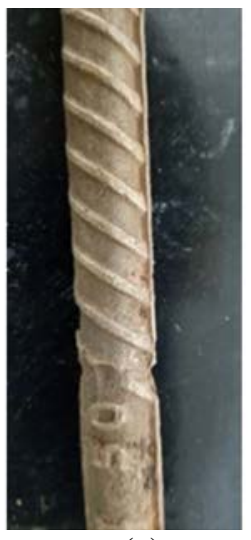

(c)

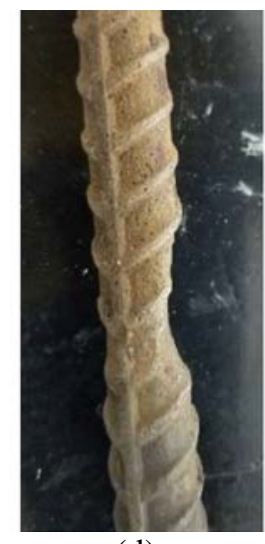

(d)

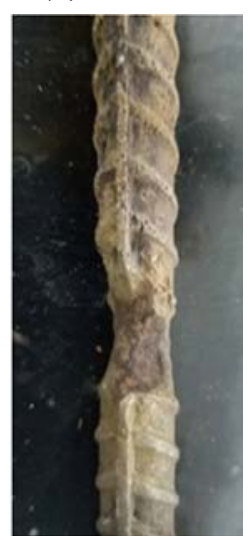

(e)

Figura 7 - Termogramas efetuados: (a) 7h00 e (b) 10h00

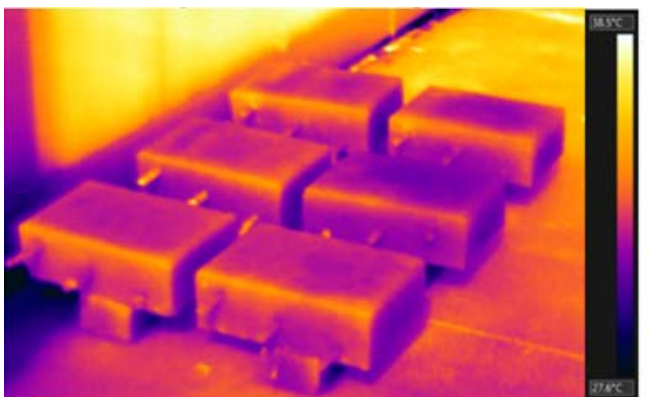

(a)

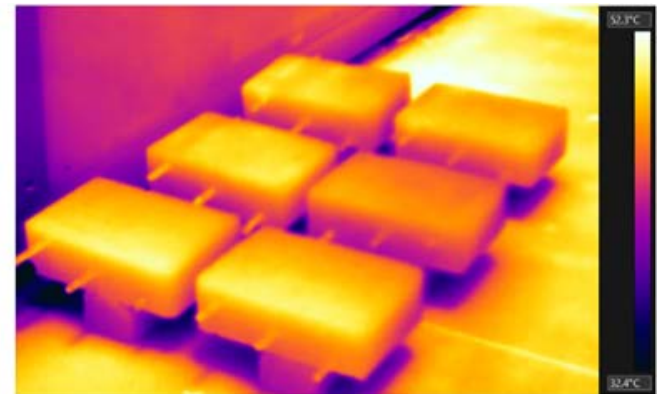

(b) 
Figura 8 - Termogramas efetuados: (a) $13 \mathrm{~h} 00$ e (b) $16 \mathrm{~h} 00$

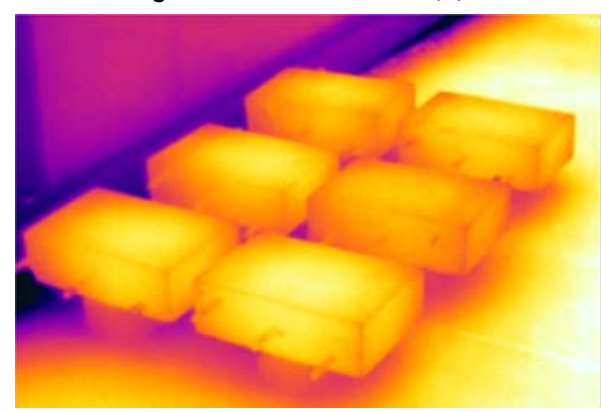

(a)
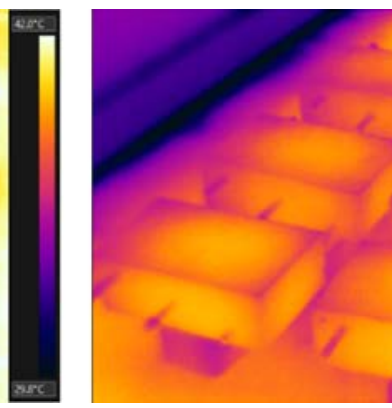

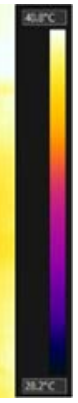

(b)

Figura 9 - Termogramas efetuados: (a) $18 \mathrm{~h} 00$ e (b) $21 \mathrm{~h} 00$

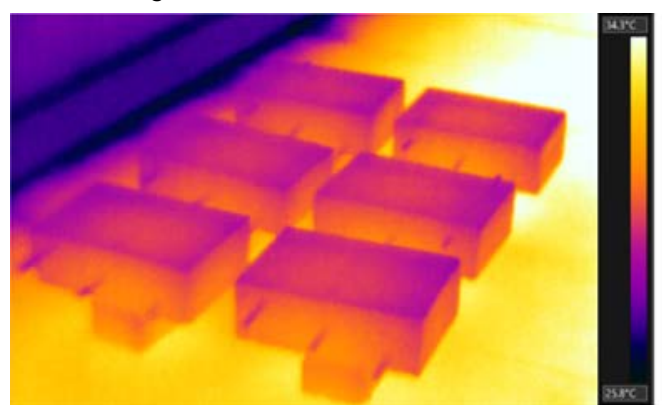

(a)

As Figuras 10 a 15 mostram o comportamento dos gradientes térmicos ao longo do dia para cada corpo de prova.

Pode-se observar que não existiram diferenças consideráveis entre a temperatura do concreto e a da superfície acima das barras, com exceção do CP5 e do CP6. Os corpos de prova CP1 e CP2 apresentaram gradientes com valores em torno de $0,2^{\circ} \mathrm{C}$, diferenças que não revelam comportamentos anômalos no concreto, conforme esperado, uma vez que não passaram pelo processo de corrosão acelerada. Os gradientes dos corpos de prova CP3 e CP4 ficaram próximos de $0,4{ }^{\circ} \mathrm{C}$, mas essas diferenças também são pequenas, pois não permitem a visualização de problemas no concreto, apesar de terem passado pelo processo de corrosão. No caso do CP5 e do CP6, os gradientes ficaram em torno de $0,8^{\circ} \mathrm{C}$. No entanto, essas diferenças apenas foram produzidas para as barras com cobrimento igual a 2,5 cm (B13 e B16), e no período das 9h00 às $12 \mathrm{~h} 00$, o que permitiu a detecção de áreas quentes em relação ao concreto sem problemas. $\mathrm{Na}$ Figura 16 são mostrados os termogramas correspondentes a esse período.

Pode-se notar que as diferenças de temperatura (gradientes térmicos) ocorreram durante o ciclo de aquecimento do concreto, o qual foi produzido pela radiação solar e pela temperatura ambiente. A transferência de calor através dos corpos de prova não foi afetada pela presença do produto corrosivo,

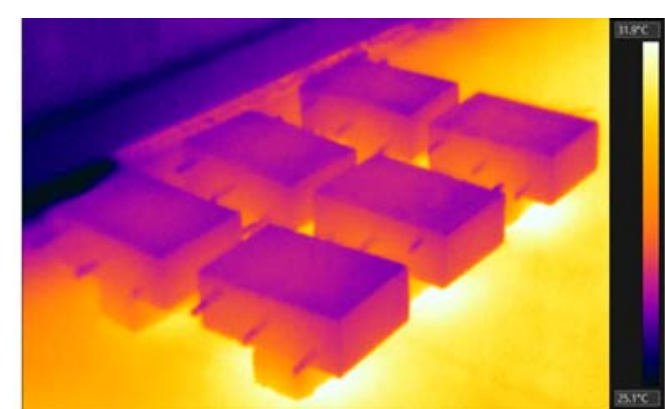

(b)

com exceção do concreto acima das barras de 2,5 cm de cobrimento do CP5 e do CP6, as quais geraram gradientes térmicos visíveis com a câmera termográfica, isto porque apresentaram perda de massa maior, gerando vazios que impediram a transferência de calor para as áreas inferiores, bem como retenção de calor na face exterior dos corpos de prova. No entanto, o período de detecção desses gradientes foi reduzido devido, principalmente, ao tamanho dos defeitos no concreto, que não eram de tamanho considerável quando comparados a outros utilizados na literatura (WATASE et al., 2015; WASHER, 2012; VAGHEFI et al., 2015; HIASA; BIRGUL; CATBAS, 2017; KEE et al., 2012).

Nas Figuras 10 a 15 pode-se observar que não pareceu existir diferença de comportamento evidente entre os concretos com diferentes relações a/c, apesar de o CP6, de menor relação a/c, ter apresentado um contraste ligeiramente maior do que o CP2, mas essa diferença foi mínima para concluir sobre a relação a/c e a detecção de corrosão.

Como visto, os contrastes térmicos menores do que $0,5{ }^{\circ} \mathrm{C}$ não permitiram a detecção de defeitos no concreto, como é mencionado na norma D4788-03 (AMERICAN..., 2013), já que essas diferenças não indicaram necessariamente problemas no concreto, pois a radiação solar refletida de outras fontes, como o piso e os próprios corpos de prova, pode 
gerar tais diferenças e ser captadas como falsas detecções.

A termografia infravermelha apresentou limitação na detecção de corrosão no aço, ficando visível apenas em barras superficiais e com maior deterioração. A profundidade máxima de detecção foi de $2,5 \mathrm{~cm}$ para perda de massa em torno de $10 \%$ (B13 e B16), para período de inspeção limitado das 9h00 às 12h00 (3 h de duração).

Figura 10 - Gradiente térmico do CP1

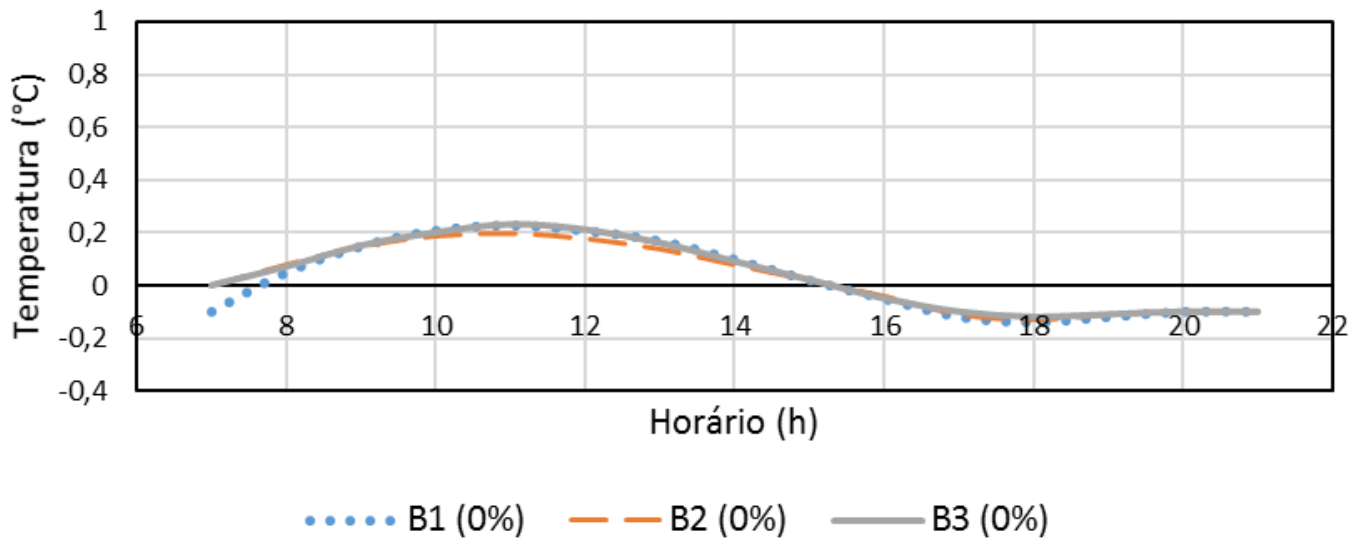

Figura 11 - Gradiente térmico do CP2

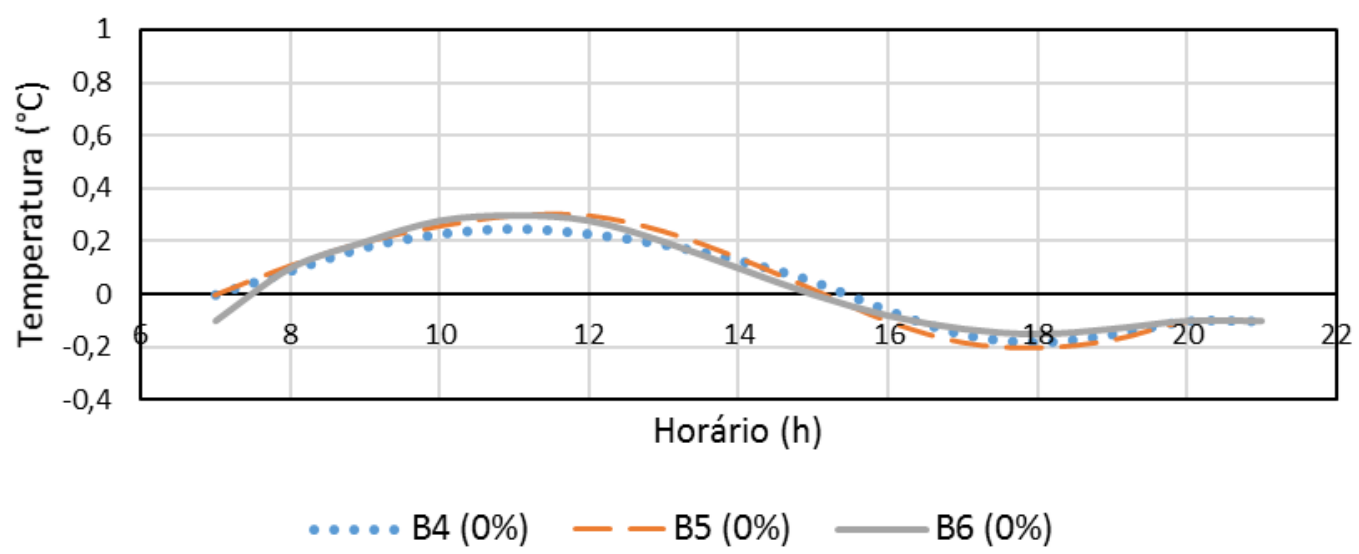

Figura 12 - Gradiente térmico do CP3

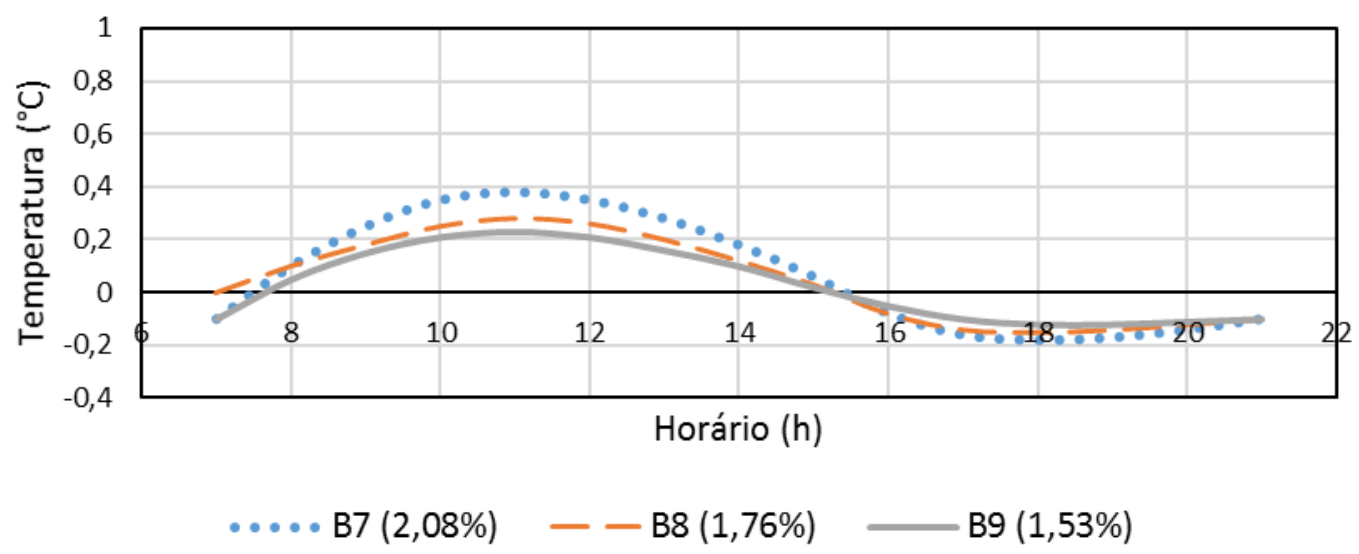


Figura 13 - Gradiente térmico do CP4

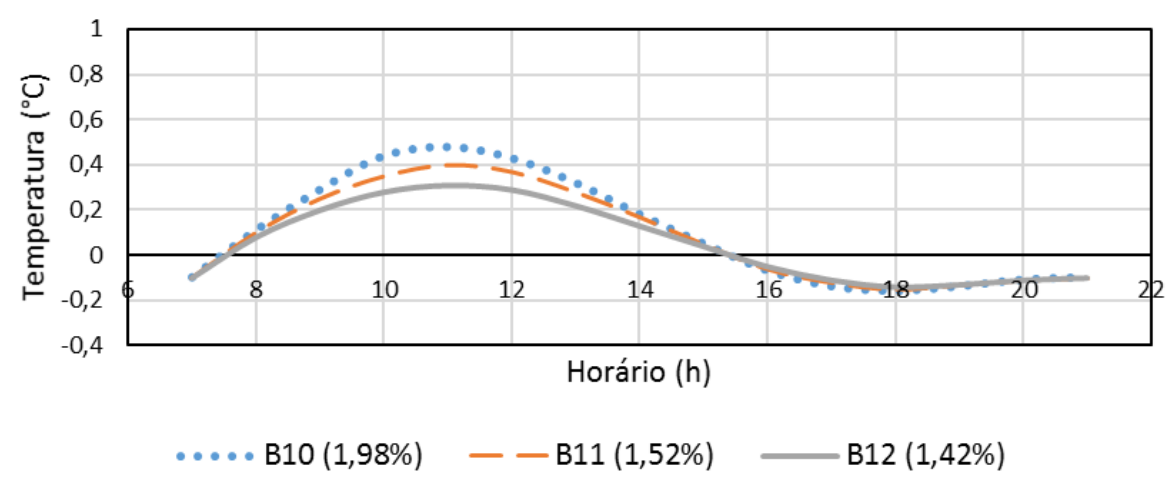

Figura 14 - Gradiente térmico do CP5

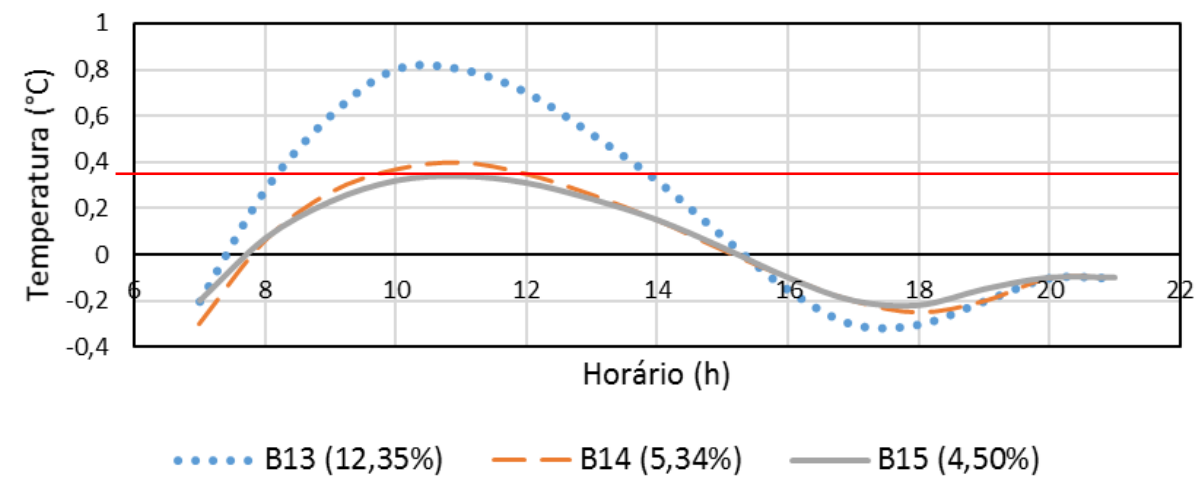

Figura 15 - Gradiente térmico do CP6

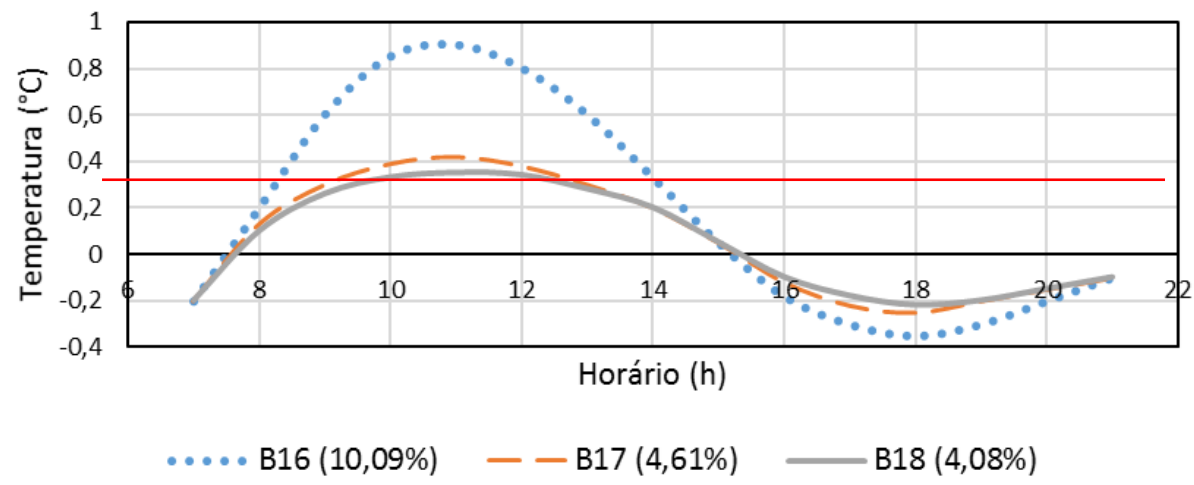

Figura 16 - Termogramas efetuados às 10h00: (a) CP5 e (b) CP6

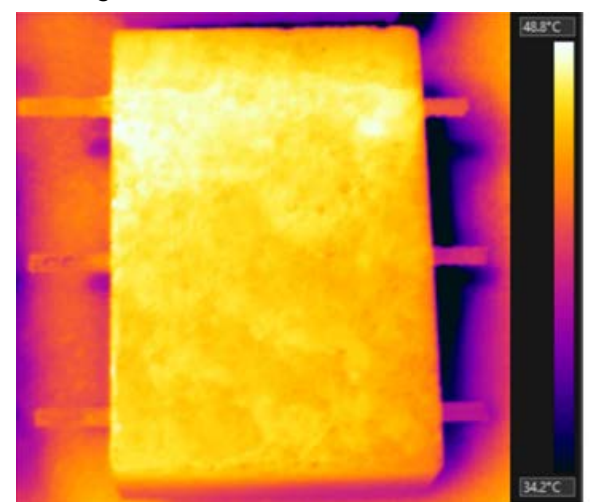

(a)

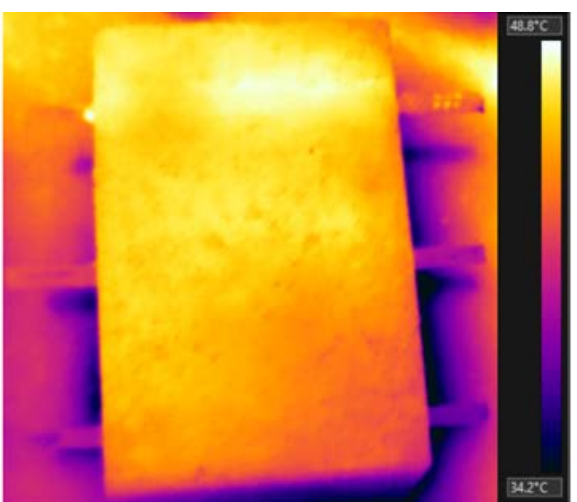

(b) 


\section{Ensaio de ultrassom}

Na Tabela 7 são mostrados os resultados obtidos no ensaio de ultrassom, bem como a velocidade média das três medições feitas em cada barra e no concreto de cada corpo de prova.

Nas Figuras 17 e 18 são mostradas as velocidades em função da relação a/c igual a 0,6 e 0,5 respectivamente.

Na Figura 17 observa-se que as velocidades de propagação da onda no CP1 (0\%) não apresentaram diferenças significativas tanto no concreto quanto nas barras, sendo valores em torno de $2.750 \mathrm{~m} / \mathrm{s}$, o que indica um concreto de qualidade regular de acordo a literatura (CÁNOVAS, 1998). No CP3 (28 dias), a velocidade mostrou variação significativa; todas as barras apresentaram velocidades baixas em relação ao CP1, com exceção do concreto, que foi afetado pelo processo de corrosão, mas em pouca medida. No CP5 (56 dias) observou-se variação ainda maior da velocidade do concreto e das barras, como também com os outros corpos de prova (CP1 e CP3), devido, principalmente, ao grau de corrosão, que neste caso foi maior, uma vez que os produtos da corrosão e a perda de massa do aço geraram vazios no concreto que impediram a livre propagação da onda, especialmente na barra com maior perda de área de seção transversal.

\section{Tabela 7 - Resultados do ensaio de ultrassom}

\begin{tabular}{|c|c|c|c|c|c|c|c|}
\hline $\begin{array}{c}\text { Corpo de } \\
\text { prova }\end{array}$ & Posição & $\begin{array}{c}\text { Tempo } \\
\text { ( } \mu s)\end{array}$ & $\begin{array}{l}\text { Velocidade } \\
\text { média (m/s) }\end{array}$ & $\begin{array}{c}\text { Corpo de } \\
\text { prova }\end{array}$ & Posição & $\begin{array}{c}\text { Tempo } \\
\text { ( } \mu s)\end{array}$ & $\begin{array}{l}\text { Velocidade } \\
\text { média }(\mathrm{m} / \mathrm{s})\end{array}$ \\
\hline \multirow{12}{*}{$\begin{array}{c}\mathrm{CP} 1 \\
(\mathrm{a} / \mathrm{c}=0,6)\end{array}$} & \multirow{3}{*}{ Concreto } & 33,1 & \multirow{3}{*}{$2.859,8$} & \multirow{12}{*}{$\begin{array}{c}\text { CP2 } \\
(\mathrm{a} / \mathrm{c}=0,5)\end{array}$} & \multirow{3}{*}{ Concreto } & 29,5 & \multirow{3}{*}{$3.446,8$} \\
\hline & & 35,2 & & & & 26,7 & \\
\hline & & 36,8 & & & & 31,2 & \\
\hline & \multirow{3}{*}{$\begin{array}{c}\text { B1 } \\
(2,5 \mathrm{~cm})\end{array}$} & 38,4 & \multirow{3}{*}{$2.794,8$} & & \multirow{3}{*}{$\begin{array}{c}\text { B4 } \\
(2,5 \mathrm{~cm})\end{array}$} & 25,9 & \multirow{3}{*}{$3.512,0$} \\
\hline & & 31,9 & & & & 33,5 & \\
\hline & & 37,8 & & & & 27,1 & \\
\hline & \multirow{3}{*}{$\begin{array}{c}\mathrm{B} 2 \\
(5,0 \mathrm{~cm})\end{array}$} & 38,5 & \multirow{3}{*}{$2.894,2$} & & \multirow{3}{*}{$\begin{array}{c}\mathrm{B} 5 \\
(5,0 \mathrm{~cm})\end{array}$} & 26,5 & \multirow{3}{*}{$3.423,5$} \\
\hline & & 30,9 & & & & 31,5 & \\
\hline & & 35,1 & & & & 30,1 & \\
\hline & \multirow{3}{*}{$\begin{array}{c}\text { B3 } \\
(7,5 \mathrm{~cm})\end{array}$} & 41,2 & \multirow{3}{*}{$2.731,7$} & & \multirow{3}{*}{$\begin{array}{c}\mathrm{B} 6 \\
(7,5 \mathrm{~cm})\end{array}$} & 29,7 & \multirow{3}{*}{$3.305,5$} \\
\hline & & 39,5 & & & & 29,9 & \\
\hline & & 30,9 & & & & 31,2 & \\
\hline \multirow{12}{*}{$\begin{array}{c}\text { CP3 } \\
(\mathrm{a} / \mathrm{c}=0,6)\end{array}$} & \multirow{3}{*}{ Concreto } & 40,8 & \multirow{3}{*}{$2.628,7$} & \multirow{12}{*}{$\begin{array}{c}\text { CP4 } \\
(\mathrm{a} / \mathrm{c}=0,5)\end{array}$} & \multirow{3}{*}{ Concreto } & 30,2 & \multirow{3}{*}{$3.309,4$} \\
\hline & & 36,5 & & & & 28,1 & \\
\hline & & 37,1 & & & & 32,7 & \\
\hline & \multirow{3}{*}{$\begin{array}{c}\text { B7 } \\
(2,5 \mathrm{~cm})\end{array}$} & 75,6 & \multirow{3}{*}{$1.483,4$} & & \multirow{3}{*}{$\begin{array}{c}\text { B10 } \\
(2,5 \mathrm{~cm})\end{array}$} & 51,1 & \\
\hline & & 68,2 & & & & 61,2 & $1.767,8$ \\
\hline & & 60,2 & & & & 58,4 & \\
\hline & & 63,5 & & & & 49,2 & \\
\hline & B8 & 59,2 & $1.573,2$ & & B11 & 53,7 & $1.871,0$ \\
\hline & & 68,7 & & & & 58,2 & \\
\hline & & 50,6 & & & & 59,2 & \\
\hline & B9 & 67,9 & $1.684,7$ & & B12 & 51,1 & $1.908,4$ \\
\hline & & 62,3 & & & & 48,1 & \\
\hline & & 38,5 & & & & 29,9 & \\
\hline & Concreto & 44,5 & $2.425,9$ & & Concreto & 33,2 & $3.085,0$ \\
\hline & & 41,1 & & & & 34,5 & \\
\hline & & 122,4 & & & & 98,1 & \\
\hline & B13 & 115,4 & 866,4 & & B16 & 102,5 & 980,9 \\
\hline CP5 & & 109,2 & & 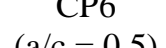 & & 105,5 & \\
\hline & & 103,3 & & & & 70,2 & \\
\hline & B14 & 98,5 & $1.031,5$ & & B17 & 79,6 & $1.337,4$ \\
\hline & $(5,0 \mathrm{~cm})$ & 90 & & & $(5,0 \mathrm{~cm})$ & 75,1 & \\
\hline & $\begin{array}{c}\mathrm{B} 15 \\
(7,5 \mathrm{~cm})\end{array}$ & 85,4 & $1.058,2$ & & $\begin{array}{c}\mathrm{B} 18 \\
(7,5 \mathrm{~cm})\end{array}$ & 75,8 & $1.381,4$ \\
\hline & & 101,5 & & & & 68,9 & \\
\hline & & 98,2 & & & & 72,8 & \\
\hline
\end{tabular}


Figura 17 - Velocidade média da propagação de onda nos corpos de prova com relação a/c $=0,6$

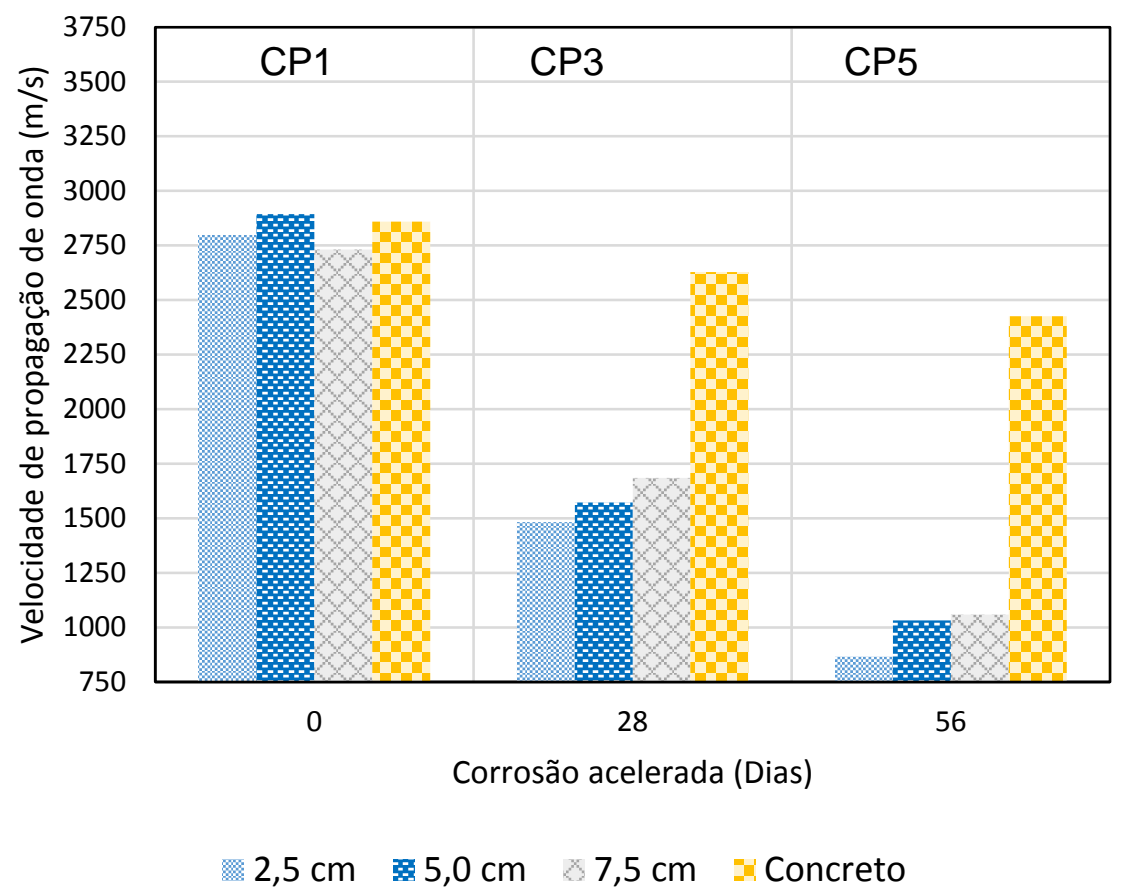

Figura 18 - Velocidade média da propagação de onda nos corpos de prova com relação a/c $=0,5$

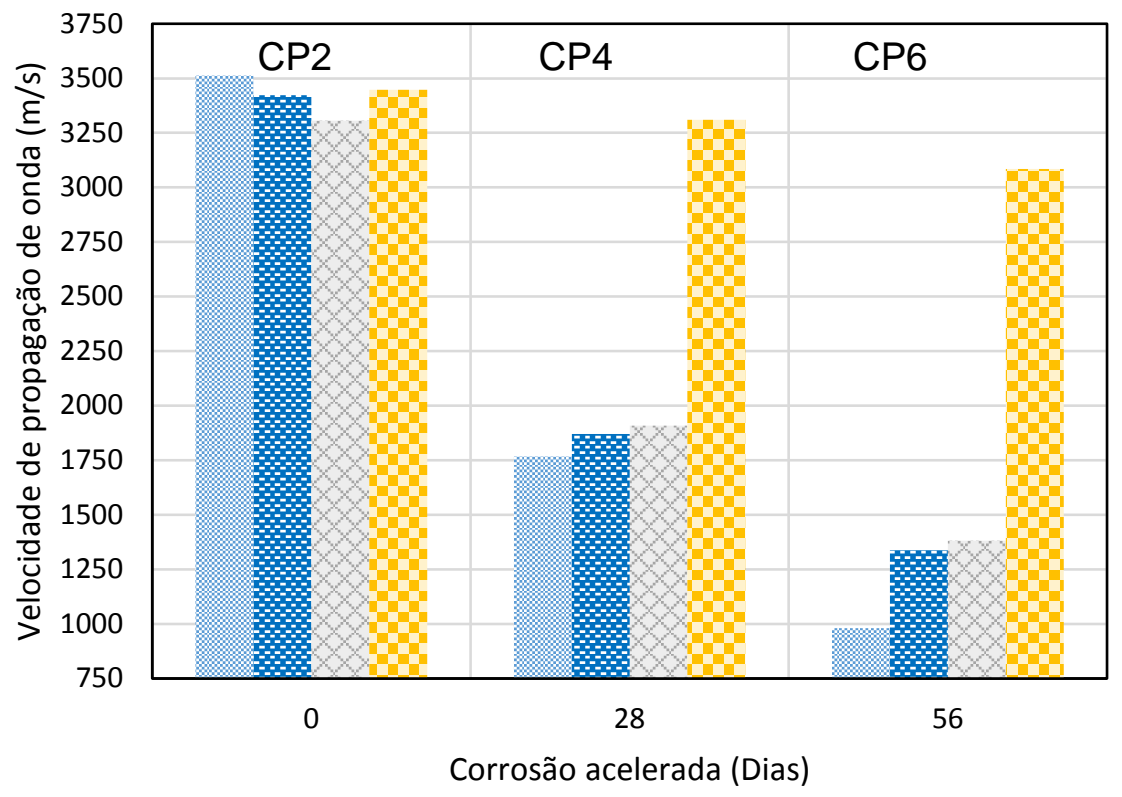

$2,5 \mathrm{~cm} \quad 5,0 \mathrm{~cm} \times 7,5 \mathrm{~cm} \quad$ Concreto

A respeito dos corpos de prova com relação a/c de 0,5 (Figura 18), observou-se que os valores da velocidade de propagação de onda foram maiores do que nos corpos com maior relação a/c em função da maior densidade, propriedade que facilita o trânsito através do material, considerando que a onda de ultrassom é mecânica e varia de acordo com o meio em que há a propagação. Descontinuidades, como vazios ou heterogeneidades, aumentam o tempo de trânsito, reduzindo as velocidades (GUPTA, 2009; GEHLOT et al., 2016). No CP2 ( $0 \%)$ os valores foram elevados, acima de 3.250 $\mathrm{m} / \mathrm{s}$, o que indica um concreto de boa qualidade (CÁNOVAS, 1998), sem grandes diferenças entre o 
concreto e as barras. Para o CP4 (28 dias) e o CP6 (56 dias), as velocidades nas áreas das barras foram baixas, especialmente na barra a $2,5 \mathrm{~cm}$, que atingiu o valor de $1.000 \mathrm{~m} / \mathrm{s}$. Como explicado, esse fenômeno foi atribuído ao produto corrosivo e aos vazios causados pela perda de massa das barras.

Pode-se notar pelos resultados obtidos que os corpos de prova com menor relação a/c $(0,5)$ apresentaram maiores velocidades de propagação de onda quando comparados aos corpos de prova com uma relação a/c maior $(0,6)$, o que indica melhor qualidade nos primeiros, uma vez que permitiu a facilidade da propagação da onda; no entanto, o produto corrosivo aumentou o tempo de trânsito em ambos os concretos analisados.

Os resultados de termografia infravermelha não conseguiram distinguir eficazmente os problemas referentes à corrosão do aço no concreto, apresentando várias limitações no tempo de inspeção e no grau de corrosão. Contudo, o ultrassom permitiu melhor caracterização da corrosão no concreto, uma vez que existiram diferenças significativas nos resultados, tanto no grau de corrosão quanto na qualidade do concreto.

Como é recomendado por outros autores (ALFREDO-CRUZ et al., 2015; AGGELIS et al., 2010; GUCUNSKI et al., 2013; KEE et al., 2012; $\mathrm{OH}$ et al., 2013), a combinação dessas técnicas analíticas permite lograr melhor detecção de problemas no concreto armado; a termografia pode localizar as barras com maior grau de corrosão, e o ultrassom pode caracterizar melhor o grau do dano em relação a outras áreas do mesmo concreto. Não obstante, como descrito, a combinação é mais sensível para estágios já avançados de corrosão.

\section{Considerações finais}

No presente trabalho foi desenvolvida uma pesquisa experimental qualitativa e quantitativa para analisar a detecção de corrosão através da termografia infravermelha e do ultrassom. Os resultados obtidos mostraram a potencialidade dessas técnicas analíticas na detecção da corrosão, observando a influência desta na temperatura superficial do concreto e na velocidade da propagação de ondas ultrassônicas através do concreto.

Concluiu-se que na detecção dos produtos da corrosão a técnica da termografia infravermelha apresentou várias dificuldades, sendo limitada às horas da manhã, das 9 h00 às $12 \mathrm{~h} 00$, e apenas em barras superficiais, cobrimentos de $2,5 \mathrm{~cm}$, que estejam em estágios avançados de deterioração, com porcentagens de perda de massa maiores que $10 \%$. Os termogramas mostraram que gradientes térmicos maiores que $0,5{ }^{\circ} \mathrm{C}$ revelam os defeitos no concreto; não obstante, os resultados não variaram segundo a relação a/c.

Já o ensaio de ultrassom mostrou-se mais sensível na detecção da corrosão devido a diferenças significativas nos resultados, tanto em corpos de prova com diferentes graus de corrosão quanto com diferentes relações a/c. As velocidades de propagação de onda em barras sem corrosão atingiram valores de $2.750 \mathrm{~m} / \mathrm{s}$ e $3.250 \mathrm{~m} / \mathrm{s}$ para as relações a/c de 0,6 e de 0,5 respectivamente; no entanto, esses valores são reduzidos quanto maior for o grau de corrosão, atingindo valores de $750 \mathrm{~m} / \mathrm{s}$ e $1.000 \mathrm{~m} / \mathrm{s}$ respectivamente em barras com perda de massa maior que $10 \%$.

A combinação de ambos os métodos permite complementar os resultados obtidos individualmente. A termografia pode localizar as áreas afetadas pela corrosão, e o ensaio de ultrassom caracterizar o grau, proporcionando melhor visão sobre a corrosão, visando diagnósticos mais precisos. No entanto, para sua implementação devem ser considerados alguns fatores, como a qualidade do concreto e as condições ambientais, no caso da termografia infravermelha.

\section{Referências}

AGGELIS, D. et al. Combined Use of Thermography and Ultrasound For the Characterization of Subsurface Cracks in Concrete. Construction and Building Materials, v. 24, n. 10, p. 1888-1897, 2010.

AHMAD, S. Techniques For Inducing Accelerated Corrosion of Steel in Concrete. The Arabian Journal for Science and Engineering, v. 34, n. 20, p. 85-104, 2009.

ALFREDO-CRUZ, R. A. et al. Evaluación de Técnicas no Destructivas en Elementos de Concreto Para Puentes. Revista Facultad de Ingeniería, v. 24, n. 40, p. 83-96, 2015.

AMERICAN ASSOCIATION OF STATE HIGHWAY AND TRANSPORTATION OFFICIALS. Manual for Bridge Evaluation. $2^{\text {nd }}$. ed. Washington, 2011.

\section{AMERICAN SOCIETY FOR TESTING AND MATERIALS. C595/C595M: standard} specification for blended hydraulic cements. West Conshohocken, 2017.

AMERICAN SOCIETY FOR TESTING AND MATERIALS. D4788-03: standard test method for detecting delaminations in bridge decks using infrared thermography. West Conshohocken, 2013. 
AMERICAN SOCIETY FOR TESTING AND MATERIALS. G199-09: standard guide for electrochemical noise measurement. Philadelphia, 2014.

\section{ASSOCIAÇÃO BRASILEIRA DE NORMAS} TÉCNICAS. NBR 5738: procedimentos para moldagem e cura de corpos de prova. Rio de Janeiro, 2015.

ASSOCIAÇÃO BRASILEIRA DE NORMAS TÉCNICAS. NBR 5739: concreto: ensaio de compressão de corpos-de-prova cilíndricos. Rio de Janeiro, 2007b.

\section{ASSOCIAÇÃO BRASILEIRA DE NORMAS}

TÉCNICAS. NBR 6118: projeto de estruturas de concreto: procedimento. Rio de Janeiro, 2014.

ASSOCIAÇÃO BRASILEIRA DE NORMAS TÉCNICAS. NBR 7211: agregado para concreto. Rio de Janeiro, 2009.

\section{ASSOCIAÇÃO BRASILEIRA DE NORMAS}

TÉCNICAS. NBR 7480: aço destinado a armaduras para estruturas de concreto armado: especificação. Rio de Janeiro, 2007a.

ASSOCIAÇÃO BRASILEIRA DE NORMAS TÉCNICAS. NBR 8802: concreto endurecido: determinação da velocidade de propagação de onda ultrassônica. Rio de Janeiro, 2013.

\section{ASSOCIAÇÃO BRASILEIRA DE NORMAS}

TÉCNICAS. NBR NM 248: agregados: determinação da composição granulométrica. Rio de Janeiro, 2003.

BAEK, S. et al. Nondestructive Corrosion Detection in RC Through Integrated Heat Induction and IR Thermography. Journal of Nondestructive Evaluation, v. 31, n. 2, p. 181190, 2012.

BARREIRA, E.; ALMEIDA, R.; DELGADO, J. Infrared Thermography For Assessing Moisture Related Phenomena in Building Components. Construction and Building Materials, v. 101, p. 251-269, 2016.

CÁNOVAS, M. F. Patologia e Terapia do Concreto Armado. São Paulo: Pini, 1998.

CONTROLS. Instruction Manual: UPV 58E4800. Italy: Controls, 2010.

FLIR. User's Manual FLIR Exx Series. Wilsonville: FLIR, 2014.

GEHLOT, T. et al. Study of Concrete Quality Assessment of Structural Elements Using Ultrasonic Pulse Velocity Test. Journal of Mechanical and Civil Engineering, v. 13, n. 5, p. 15-22, 2016.
GUCUNSKI, N. et al. Non-Destructive Testing to Identify Bridge Deck Deterioration. $2^{\text {nd }}$. ed. Washington: SRHP, 2013.

GUPTA, M. K. Guidelines on Non-Destructive Testing of Bridges BS - 103. New Delhi: Ministry of Railways, 2009.

HERNANDEZ-VALLE, F.; CLOUGH, A. R.; EDWARDS, R. S. Stress Corrosion Cracking Detection Using Non-Contact Ultrasonic Techniques. Corrosion Science, v. 78, p. 335-342, 2014.

HIASA, S. Investigation of Infrared Thermography for Subsurface Damage Detection of Concrete Structures. Orlando, 2016. $224 \mathrm{f}$. Thesis - University of Central Florida, Orlando, 2016.

HIASA, S.; BIRGUL, R.; CATBAS, N. F. A Data Processing Methodology for Infrared Thermography Images of Concrete Bridges. Computers and Structures, v. 190, p. 205-218, 2017.

KEE, S. et al. Nondestructive Bridge Deck Testing with Air-Coupled Impact-Echo and Infrared Thermography. Journal of Bridge Engineering, v. 17, n. 6, p. 928-939, 2012.

MEHTA K. P.; MONTEIRO P. Concrete: microstructure, properties, and materials. 4. ed. New York: McGraw-Hill, 2013.

MEIRA, G. R. Corrosão de Armaduras em Estruturas de Concreto: fundamentos, diagnóstico e prevenção. João Pessoa: IFPB, 2017.

MORENO, E. Corrosión de Armaduras en Estructuras de Hormigón: estudio experimental de la variación de la ductilidad en armaduras corroídas aplicando el criterio de acero equivalente. Leganés, 2008. 345 f. Tese (Doutorado) - Universidad Carlos III de Madrid, Leganés, 2008.

$\mathrm{OH}$, T. et al. Comparison of NDT Methods for Assessment of a Concrete Bridge Deck. Journal of Engineering Mechanics, v. 193, n. 3, p. 305314, 2013.

VAGHEFI, K. et al. Combined Imaging Technologies for Concrete Bridge Deck Condition Assessment. Journal of Performance of Constructed Facilities, v. 29, n. 4, p. 1-8, 2015.

WASHER G. Advances in the Use of Thermographic Imaging for the Condition Assessment of Bridges. Bridge Structures, v. 8, n. 2, p. 81-90, 2012. 
WASHER, G.; FENWICK, R.; BOLLENI, N. Development of Hand-held Thermographic Inspection Technologies. Jefferson City: Modot, 2009.

WATASE, A. et al. Practical Identification of Favorable Time Windows for Infrared Thermography For Concrete Bridge Evaluation.

Construction and Building Materials, v. 101, n. 1, p. 1016-1030, 2015.
ZOU, X. et al. Nondestructive Corrosion Detection Using Fiber Optic Photoacoustic Ultrasound generator. Measurement, v. 62, p. 74-80, 2015.

J oaquin Humberto Aquino Rocha

Escola Politécnica | Universidade de Pernambuco | Rua Benfica, 455, Madalena | Recife - PE - Brasil | CEP 50720-001 | Tel.: (81) 31847566 | E-mail: joaquinaquinorocha@gmail.com

Yêda Vieira Póvoas

Escola Politécnica | Universidade de Pernambuco | Recife - PE - Brasil | E-mail: yeda.povoas@gmail.com

Revista Ambiente Construído

Associação Nacional de Tecnologia do Ambiente Construído

Av. Osvaldo Aranha, 99 - 30 andar, Centro

Porto Alegre - RS - Brasil

CEP $90035-190$

Telefone: +55 (51) 3308-4084

Fax: +55 (51) 3308-4054

www. seer. ufrgs. br/ ambienteconstruido

E-mail: ambienteconstruido@ufrgs.br

(c) (i) 